\title{
Dances across the boundary: Banande and Bakonzo in the XXth Century
}

\section{Serena Facci}

Dances, songs and instrumental music are a meaningful element in the construction of identity and cultural boundaries. In many cases, and above all in situations of conflict, a specific repertory, or a song, a dance, an instrument can become the symbol of a nation or a region (just think of the Irish harp, the Catalan sardana, the Sardinian canti a tenores).

On the other hand, music, which is a 'volatile' art, is more susceptible and open to crossfertilisation than other forms of expression. Through contact with the musics of other groups, social classes or people, far and near, musicians from every part of the world see opportunities to enrich and renew their art.

In music, the concept of boundary is therefore questionable to say the least. As with many other experiences, music in this case reveals its functional and apparently contradictory duplicity. It is a communicative system that is able to favour both the isolation of individuals and peoples, and the sharing or even collectivisation of experiences.

There may be countless reasons for moving forcefully in one direction or the other, and all of them can be located within the complex interstices of historic dynamics.

For some decades now, in a period that is today defined even in cultural terms as post-colonial, ethno-anthropological studies have abandoned some assumptions that were characteristic of such disciplines at the outset. Amongst these was the idea that societies, particularly pre-industrial ones, with which contact was made during research activity, could be perceived and described as stable and immobile entities. Concepts such as cultural fluidity, "originary syncretism" 1 , continual renegotiation of identities, etc, have gradually become more pertinent and useful in understanding what happens in various parts of the world, together with a rediscovery of a diachronic approach to events.

In this article, and using this perspective, a particular research experience, which has been carried out in the Rwenzori area since 1980s, will be analysed. The populations referred to, the Banande and Bakonzo, are settled around a boundary: first geographical (the two sides of the massif, the two shores of Lake Edward); and then political (the colonial and post-colonial border between Uganda and Congo).

John Blacking in 'A Commonsense view of all Music' writes:

Dance and song can be understood as primary adaptations to environment, with them, mankind can feel towards a new order of things and feel across boundaries, while with speech, decisions are made about boundaries. This is why, even in industrialized societies, the changing forms of music may express the true nature of the predicament of people before they have begun to express it in words and political action ${ }^{2}$.

In the subsequent lines, Blacking uses the situation in South Africa as an example when, during the tough years of apartheid, the township musics with their sound content anticipated the political protest movements against the racist white regime.

In our case, the idea of boundary, which has been continually renegotiated in the pre and postcolonial history of these twin African populations, will be explored by starting with an analysis of the dance repertory.

The names attributed to these dances and, in general, the terminology used, the occasions in which they were or are performed, the choreographies, the movements, and the instrumental backing

\footnotetext{
${ }^{1}$ Definition in Amselle, Mestizo Logics, 1.

2 Blacking, 'A Commonsense view of all Music', 60.
} 
formations, will all be useful clues in reconstructing a hypothetical history. This will, of course, be the history of the dances, of how they are considered, set within their system of customs and values, and of how they have evolved, indicating the differentiation between these two peoples, separated by the colonial border. At the same time, however, it aims to be the story of how groups of people define themselves through their dances and how, with these dances, they have come into contact with each other, with neighbouring peoples, with the colonial forces, and with the modernity that has been diffused by the media.

As Curt Sachs said, among the various forms of art expression, dance is perhaps the most complete: it lives in the time and in the space. ${ }^{3}$ Between musical expressions, dance is the most immediate. Song, in fact, in its logogenic forms, is mediated by verbal language which is semantically unequivocal; instrumental music is mediated by the technology of the instrument which forces one to build a relationship with an object; in dance, we are in the front line, revealing ourselves in our bodily dimension.

Corporeal expressiveness is exalted in dance, but at the same time it is structured in organised and stereotyped ways, particularly in the socially shared dances, as is largely the case with the Banande and Bakonzo people whose songs and dances I will analyse. Studies in Anthropology and Sociology of dance claim that dance is undoubtedly the most culturally determined of the various ways that people demonstrate their bodily presence in the world. The natural limits of corporeity seem to be most severely tested particularly when dancing, and the gestural differences between one experience and another become more sophisticated at that level. ${ }^{4}$

Dance, inasmuch as it is gestural expressiveness of a collective, organised and public sort, thus becomes one of the most direct means that a population or a group has of portraying itself. In studies on Africa, correct emphasis has very often been laid on the relationship between traditional dance and life experiences, both ordinary and extra-ordinary. Maurice Sonar Senghor, the founder and long-time director of the Theatre National "Daniel Serano" in Dakar, stated in a 1971 interview reported by Doris Green, that "before a dance can be created, an event or happening must occur". 5 In order for these events or gestures of everyday life to become dance, someone has to create original patterns of movement that come to be part of a new perception and portrayal of self. This process should be understood first and foremost from the point of view of its aesthetic motivations. The new dimension, the artistic one, can then proceed along autonomous paths of development, and give birth to different relationships with new facts and events, in a constantly renewable circuit. 6

These processes are, I believe, recognisable in the dances of every group of people, including the Banande and Bakonzo.

The Ba-nande and the Ba-konzo speak the same language, have the same clans, and the same economic and family organisation. The two groups appear to stem from a single population, the

\footnotetext{
${ }^{3}$ Sachs, Eine Welgeschichte des Tanzes: 21(Italian Edition)

${ }^{4}$ See Hanna. To Dance is Human, Peterson Royce, Anthropology of dance, for the anthropological approach and Thomas, Dance, Modernity and Culture, for the sociological. We should also remember an aspect which will not be tackled in this essay: the codification of gestures makes dance one of the possible therapeutic paths for confronting psychic disorders. Its use is wellestablished in many traditional therapeutic practices throughout the world, including Africa, through dance therapy. There is also a reference in Lowen, The Language of the Body, with regard to how schizoid patients seek a response to their personality disorders in the rules of movement imposed by dance.

${ }^{5}$ Green, Traditional dance: 14 .

${ }^{6}$ For a (post-colonial) aesthetic perspective in approaching the history of African dance and its Afro-American offshoots, see Welch-Asante (ed), African Dance.
} 
Ba-Yira, once resident in what is today known as Uganda, probably in the territories belonging to the ancient kingdom of the Bunyoro people. According to some interpretations, it was the Zanzibari traders and slave-runners who coined the terms Banande, or Wanande, derived from the Swahili "wanaenda" (those who go) and Bakonjo, or Bakonzo, which means "those who are in poor health, who live in backward conditions" ${ }^{\prime 7}$

The two groups experienced a separation, which we can divide into three phases.

First phase. In the pre-colonial period, the present-day Banande probably crossed Lake Edward and the slopes of the Mountains of the Moon, pushing on towards the interior of the continent in search of new lands to cultivate. The migratory flow probably began at the beginning of the $19^{\text {th }}$ century, or perhaps even earlier. The Bakonzo people, who remained on the eastern slopes of the Ruwenzori massif, found themselves involved during the 19th century in the birth of a new kingdom, that of the Batoro people, which emerged from a rebel cadet of the ruling family in Bunyoro. The relationship between the Bakonzo and the Batoro, which was initially one of alliance, soon became extremely confrontational, and during the colonial period eventually gave birth to a nationalist rebel movement, the Rwenzururu Movement, whose aim was to create a kingdom for the Bakonzo. The Banande, on the other hand, pioneers in a new land, were exposed to contact with new Bantu and pygmy populations living in the forest, over whom they probably became dominant.

Second phase. The arrival of Europeans at the end of the 19th century had already led, by the time of the 1885 conference in Berlin, to the defining of a border between the Free State of the Congo, entrusted to King Leopold II of Belgium, and the English Protectorate of Uganda. For the Banande-Bakonzo, this border had various consequences:

- The defining, through an administrative act, of a fluctuating separation.

- A differing colonisation process which caused the two groups to be involved in different histories. Without going into detail, suffice it to say that the Banande territories under Belgian domination were, from the very beginning, directly controlled by the Europeans who worked, in particular, towards exploiting the numerous, different mineral resources. The Bakonzo on the other hand remained relatively isolated, since the English preferred to entrust the control of the mountainous Ruwenzori territory to their Batoro allies. In other words, the Banande were in a prime position compared to the neighbouring African populations, but were more exposed to European control/confrontation, whereas the Bakonzo were subject to other African peoples, but in a situation of partial isolation in relation to the european.

- We can speak likewise of a different kind of Christianisation: in 1906, the Sacred Heart Missionaries or Dehonians, who came from the Haut Congo, built a first chapel near Beni, in Nande territory (which then became the Mission de Saint Gustave). In 1928, different French missionaries, the Assumptionists, took over from the Dehonians. The Konzo territory was in the Diocese of Fort Portal, in the territory of the Batoro people. The first Catholic church in Nsenyi and the first Anglican church in Bwera were both built in 1938 and both priests and clergymen were Africans. ${ }^{9}$ A Catholic priest told me that the white missionaries in Uganda did not go into the areas of the Rwenzori which were thought to be too harsh and inhabited by primitive people. ${ }^{10}$

\footnotetext{
${ }^{7}$ Mashauri, Organisation étatique des Yira.

${ }^{8}$ For a recent synthesis of the historiographical hypotheses, see Pennacini, Alle falde del Ruwenzori.

${ }^{9}$ The first catholic parish priest in Nsenyi was Ph. John Balyghugha. Interview to Ph. Balinande, historian and musician, Kasese, August 2007.

${ }^{10}$ P. Cyriaco Toxton Ajiga, parish priest in Ibanda (Kasese District, Uganda), interviewed in August 2007.
} 
Throughout the 20th century, contact between the two peoples and migratory movements from one part to the other never ceased. In 1908, Jan Czekanowski, an anthropologist and ethnologist who was a member of a German scientific expedition in the area, reported that there were Bakonzo people who escaped to the Belgian Congo to avoid paying Batoro taxes. ${ }^{11}$ On the other side of the border, the Banande praised the English area which "devenait, dans leur récits un veritable paradis" 12 . In the Thirties, there was an intense migration by the Banande towards Uganda. The son of one of these immigrants told me that his father had escaped because "The Belgians were terrible" 13 .

Third phase. The Congo and Uganda also had different post-colonial histories. For reasons of interethnic equilibrium, the two Republics have maintained their colonial languages as official languages. For this reason, the Banande and Bakonzo, who still speak the same language, the Banande study French at school and the Bakonzo study English but both share the same vernacular languge. Despite this fact, the border is still relatively fluid for business people and family members. The Bakonzo say that merely by crossing the border, they become Banande, and vice versa.

The Rwenzururu Movement has now obtained recognition from the republican government of Uganda for a newborn Konzo monarchy. ${ }^{14}$ The movement's representatives pursue the dream of reunification with the Banande people, at least as an ideal. The movement delegate responsible for organising the ceremony on the return of king Charles Wesley Mumbere ${ }^{15}$ to his country and subsequent wedding (which took place on $19^{\text {th }}$ October 2007), told me that representatives of the Banande people would be invited to the wedding and that collaboration between the two peoples would be extremely advantageous to both: the Bakonzo, thanks to their domination by the English and the political choices of the current government have excellent hospitals and schools, whereas Nande business people in Congo can accumulate a wealth unheard of amongst the Bakonzo. "Noone here can have an airplane like the businessmen of Butembo". ${ }^{16}$ This means that, despite everything, the Congolese territories of the Banande, even though badly governed and tormented by a long civil war during last decades, still offer better economic opportunities than the multi-ethnic portion of Uganda close to the border where the Bakonzo live.

\section{NANDE DANCES - KONZO DANCES: ETHNOGRAPHIC COMPARISON}

\section{The common heritage: dances and the cycle of life}

The dances common to both the Banande and Bakonzo are mainly ritual and linked to the cycle of life. More than a truly common repertory, they form a common memory, since in large part they have fallen into disuse and, at least among the Bakonzo, are chiefly performed during the shows put

\footnotetext{
${ }^{11}$ Czekanowski, Carnet de route au coeur de l'Afrique : 154.

12 "In their tales, became a true paradise." Id..

${ }^{13}$ Kambale Wilson, head of the Kasese school district (Uganda), interviewed in August 2007.

14 The need for a monarchy to be recognised intensified after the republican government of Uganda decided, in 1993, to reinstate the ancient kingdoms, attributing to them even some prerogatives regarding the administration of the territory and, above all, the management of their cultural heritage. The kingdoms recognised were the four main ones: ganda, nyoro, toro, ankole. For information on the Rwenzururu Movement rebellion, see Stacey, Tribe, and Cooke, Doornbos, Rwenzururu Protest Songs.

${ }^{15}$ Charles Mumbere was in exile for many years in the USA.

${ }^{16}$ Katya Aganatya, interviewed in August 2007.
} 
on by the so-called Cultural Groups, or are studied at school during the lessons in musical education.

In my opinion, however, these dances testify that, in the pre-colonial and above all pre-Christian period, the two populations shared customs and beliefs which were of outstanding importance to the life of their communities.

\section{Birth Dances.}

In 1988, in Lukanga in the D. R. of the Congo, I met a group of Nande avakekulu (older women). ${ }^{17}$ They were working in a medical dispensary run by an Italian obstetrician, Concetta Petriliggeri, who, recognising their skills as village midwives, had trained them in European obstetric and health procedures.

This group of women presented some dances that were traditionally performed at birth.

The ritual cycle was linked to two particular moments: 1) the delivery and cutting of the umbilical cord at which only women were present (until the cord fell off the mother and child were in a kind of segregation 2) the subsequent introduction of the baby and mother to the community, during a celebration.

The dances and songs related to birth were performed above all at this moment.

On that occasion, it was possible to acquire documentation with video and audio recordings of the songs ${ }^{18}$ and dances which were accompanied by an ensemble of three drums. The dances had a relatively free choreography. The women danced adopting postures, and movements of the feet and shoulders that were common to the majority of Nande dances; in two cases, the omwimbiriri, or solo female singer, who was also the group leader, performed pantomime dances, miming with the aid of objects the stages of grinding millet and preparing food, and the different ways in which newborn babies are held in a woman's arms or tied to her back.

In 2007, I interviewed some women in Ibanda (Kasese district), Uganda, about the traditional ceremonial rituals linked to birth. ${ }^{19}$ An old lady, Elisabeth Mambo, remembered very well how, when the woman who had given birth came out of segregation, she was made to sit in the place where the celebration occurred, and how all the women sang, dancing a specific cycle of songs. So the procedures for the celebration of the newborn child and new mother seemed to be quite similar to those of the Banande.

I proposed that the Konzo women listen to the songs of the Nande midwives recorded in Lukanga in 1988. The comparison revealed that the contents and, in one case, even the melody were very similar. With regard to the dances, Elisabeth said that they danced around the new mother in a relatively free manner, as the old Nande women probably did, too.

The Bakonzo also spoke of particular celebrations and song repertories performed after the birth of twins or albinos. Both types of birth are considered to be extraordinary events for which contact with the spirits must be made so as to re-establish an order that has been disrupted. The Banande also had specific songs for twins.

Even though they are rarely performed today, the birth songs and dances confirm a consistent homogeneity between the two cultures, which was probably stronger in the past when these kinds of rituals were constantly practised.

\section{The omukumu, or male initiation dance.}

\footnotetext{
${ }^{17}$ The term indicates the highest age bracket for a woman. We could link it to the period of a woman's life in which she is no longer fertile. Generally, older women, who are respected for their experience, are granted prerogatives that are not usual for women, such as the use of musical instruments.

${ }^{18}$ The text and comment on these songs can be found in Pennacini, Danze nande.

19 They are Elisabeth Mambo, the women of the association, IbandarRural Women for Sustainable Development, and those of the Maliba Cultural Group.
} 
This dance was performed by the young men, both Nande and Konzo, during the period when they were segregated in the forest for circumcision, olusumba ${ }^{20}$. Amongst the Banande people, there was little verbal evidence. The musicians and other men I interviewed, were extremely unforthcoming on this subject, since all the procedures linked to male initiation were kept entirely secret from women. So I have no visual or sound documents of either the dance or the instrument. However, amongst present-day Bakonzo, who still practise circumcision but have lost the custom of ritual segregation in the forest, one can attend performances by Cultural Groups and school groups, in which the omukumu is performed in public. The choreographies are obviously affected by the needs of the performance, and have in part changed compared to those performed in the forest in the past, but it is clear that both the Banande and the Bakonzo had a specific dance and a specific instrument, called omukumu, that characterised male initiation.

During the omukumu, the dancers hold sticks of different lengths in their hands which they strike with a baton. The rhythmic co-ordination must be such that it creates a melodically coherent interweaving with the totality of single sounds produced by each dancer.

This polyphonic practice (defined as "hocket" ${ }^{21}$ by Africanist musicologists) is very frequent in Africa, and also Uganda, in trumpet or stopped flutes orchestras. The Bakonzo-Banande perform it in a dance that is always exclusively male, in which each dancer plays a whistle of a different length. The complex of these flutes is called eluma or, only among the Banande, amalenga.

\section{The funeral dances: amasinduka and omukobo.}

More than a dance, the amasinduka is a ceremonial-celebrative funeral cycle. By analogy, as often occurs in Africa, the term is also used to indicate the songs and dances performed on that occasion. Today, it is no longer practised among the Bakonzo and, even back in the Eighties, it was no longer performed amongst the Banande. Everyone, however, remembers its function: for the Banande (much concerned with the distinction of gender, as we shall see), it related to ceremonies devoted to the death of a woman, for the Bakonzo, there is no distinction between the sexes.

As on other occasions, I could see that the Bakonzo had a clearer memory of the ceremony's structure, even though the interviews took place twenty years after its disappearance, and so in a period following their exposure to modernisation and foreign cultures also through the media ${ }^{22}$. We know that the Bakonzo are more linked to their area of origin, but it cannot be excluded that the need to distinguish themselves from the neighbouring peoples, strengthened in recent years by the work of the Rwenzururu Movement, has led many of them (particularly in the schools and among young people) to adopt a more conservationist approach towards tradition and, in some cases, one of revival.

The omukobo is quite a spectacular dance in which two dancers, dressed as warriors, confront each other, miming a duel. All the eye witnesses, both among the Banande and the Bakonzo, concur in defining it as a dance devoted to older and particularly remarkable men, such as great warriors, sages, and men who are important at a political level.

${ }^{20}$ The olusumba, practised in Uganda by the Bakonzo and Bamba, is not found among the neighbouring populations and, therefore, makes the Bakonzo a sort of special case in the area of West Uganda, together with other cultural traits such as the language and scales in music which are not pentatonic.

${ }^{21}$ Arom, Polyphonies et polyrythmies.

${ }^{22}$ Consider the fact that in the areas inhabited by the Banande in the Eighties, there was no electricity, few people had a radio and, in the villages and small towns, nobody had television. The situation of the present-day Bakonzo is very different: they use cell phones and do not lack knowledge of the computer and internet. 
It has not been in use for a very long time. In the Eighties, however, it was possible to film a version among the Banande, performed by two young men, one armed with the traditional lance and another with a wooden gun.

In this categorization of ceremonial dances linked to topical moments in the cycle of life, the wedding dances are missing.

The dances performed during weddings are still very much alive and are decidedly different between the two peoples. For this reason they will be introduced separately, amongst the divergent cases.

\section{The divergent cases}

\section{Engwaki, erighomba: dances and politics}

The Nande musicians employ particular music and dance during the critical moments following the death of a chief ( $m$ wami) and the enthroning of his successor (particularly of the chiefs of larger clans like the Baswaga, the Bamate and the Batangi), even though in the Eighties, these ceremonies had not been performed for many years because the chiefs were all in good health. ${ }^{23}$ Two musicdances, typified in essence by the use of special drum sets, formed part of these rituals in two different clans: the engwaki for the Baswaga and the erigomba for the Batangi. None of the Bakonzo people I met, many of whom were of the Baswaga clan, knew these music-dances. There are so many non-witnesses that I tend to think these dances never existed amongst the Bakonzo. Throughout the entire 20th century, the Banande lived in an area where they were freer to practise some customs belonging to the public and political sphere. Both the Belgians and the English tolerated the local authorities, such as the mwami, with whom they tended to form alliances so as to control the territory better. But the relationships that the Bakonzo and Banande had with other African peoples were different.

The Banande in the interior areas of the continent found themselves in a dominant position with regard to the pygmies and small local groups of Bantu speakers.

The situation of the Bakonzo was completely different. They were subjects of the Batoro kingdom and, as such, were probably not as free to practise ceremonies that celebrated the heads of their clan. The most important administrative figures among the Bakonzo people, even today, are the crest-chieftains, i.e. the people who control portions of the mountain territory. The rituals practised by these important figures, with accompanying dances, are performed periodically to purify the crests from the negative influences of spirits. These rites are more meaningful at a religious level than as a celebration of the chieftain's personality. Among the procedures underway for the construction of the Konzo monarchy, the Rwenzururu Movement is currently defining a court ceremony which also foresees a musical protocol. Here, the Bakonzo's traditional music is blended with elements of the political-musical symbolism of other Ugandan kingdoms, in particular the sacredness of royal drums. ${ }^{24}$

It is not so strange therefore that the present-day Bakonzo do not seem to know the engwaki and the erighomba. What one should ask oneself is if the Banande took their old customs with them or if, instead, they constructed a new musical identity in the Congo that was linked to politics, just as the Bakonzo are doing today.

\section{Amatakio, omunde, ekikebi, engwayo : wedding dances, eroticism and Christianisation}

\footnotetext{
${ }^{23}$ With regard to these rituals, see the testimony of Bergmans, Nova et vetera, and the reconstructions by Remotti, Etnografia nande I.

${ }^{24}$ On court music in the largest Ugandan kingdom, that of the Baganda, see the recent work by G. Kubik, Nuove ricerche sul campo nel regno del Buganda.
} 
One of the things that struck me the most while watching the Konzo dances was the fact that men and women had different styles and roles but could share in all the dances whereas many of the Banande dances are specifically male or female. ${ }^{25}$

For the Bakonzo, ekikebi means both a style of dance, typified by a rapid oscillation backwards and forwards of the chest (ekikuba), and a specific courtship dance in which men and women stand facing each other in two different lines that approach and then move apart. ${ }^{26}$

In the centre of the choreographic space, the meeting and formation of momentary couples occurs, who then dance together for some moments in different routines, some of which have an erotic content, before moving apart and beginning another cycle. The ekikebi, both as a style and as a choreography, is always associated with joyous occasions. It is performed at weddings, but we have also seen it in theatre performances where it marks the happy ending of the story. Amongst the Banande people, the dances that were most representative (together with the endara) were the amatakio, performed by young unmarried women, and the exclusively male omunde, both of which were used at weddings.

The omunde was defined as "the sparrowhawk's dance" ${ }^{27}$. The basic choreography was a semicircle, but the dancers often broke free from it to perform routines of particular complexity, also adopting some postures typical of this proud bird of prey. The symbolic content of this dance can be traced back to the portrayal of male vigour. The erotic movements, although present, are very limited and inserted into a context that principally recalls (in the songs, too) male complicity, manifested through the collective demonstration of strength and dexterity. The dancers wear heavy ankle bracelets with iron bells and their skill is measured by the number of bells that they can carry. Even though it is entirely different on a formal-stylistic level, the omunde brings to mind male dances such as war dances or initiation dances.

The amatatakio, on the other hand, appears to be a portrayal of female kindness. The girls arrive in procession. They stand in two lines which face each other (as in the Konzo ekikebi) and chant a series of songs, many of which recount events and rules of conjugal life, as often occurs in the wedding songs. When a song finishes, two girls step out, from different lines, and meet in the middle, thus creating a couple which takes on the role of leader in the subsequent song and dance. The wedding is therefore celebrated, in its dancing, through a separation of the sexes. The reason for this was suggested to me by the Banande themselves. In the village of Magerie, several older people were persuaded to demonstrate some ancient love dances, such as the erisole and the engwayo, which were by then rarely performed. ${ }^{28}$ The former takes its name from a bird and the movements of the men imitate the courting dance. The engwayo, despite its different name, has an extremely similar choreographic set-up to that of the Bakonzo's ekikebi: men and women in two separate lines dance face to face until someone steps forward into the central space, that of the meeting, and choosing a partner, performs some suggestive couple movements.

\section{Figure 1 Konzo ekikebi dancers}

Thus the distance between the Bakonzo and the Banande must once have been less radical. There may have been numerous factors that caused them to move apart, but in primis the influence exerted by the Missionaries should be taken into account. One of the problems that European Catholic priests felt most strongly when they arrived in Congo was undoubtedly that of sexual and family customs. Extramarital relationships and, in particular, polygamy were a supreme source of

\footnotetext{
${ }^{25}$ See also Facci, Nanyonga Tamusuza, Continuity and Change in Bakonzo Music.

${ }^{26}$ Mbabazi, Kikibi dance.

${ }^{27}$ Waswandi, Le Munde.

${ }^{28}$ Interviews with the elders in the village of Magerie (North-Kivu) in July 1988.
} 
worry $^{29}$. The mixed dances with their erotic content must have been gradually forbidden and uprooted.

In July 1988, I was invited to present my work during a public debate at the Catholic Mission in Lukanga (North-Kivu). When I said that I had noticed that many dances were falling into disuse, a woman intervened, relating that it was precisely the priests who had banned them because they were considered scandalous. Likewise, in 2007, I met a Nande nun in Ibanda (Uganda) ${ }^{30}$. She agreed with me that the Bakonzo dances were more sexually free than those of the Nande, and that the reason was above all in the different process of Christianisation. She was also amazed at how, even today, so many Ugandan women could put up with polygamy, a custom which is by now much less widespread among the Banande.

\section{The endara: dances and traditional religion}

The endara is a large xylophone set on banana tree trunks, much loved both by the Banande and the Bakonzo. The dance performed around the endara is very popular and anyone can freely take part in it. Some songs performed on the xylophone are common to the two groups, as are also the performance methods (an endara is always accompanied by three drums).

Yet there is a significant difference in the meaning that this instrument has acquired for the two peoples. For the Bakonzo, the endara is associated with many ritual occasions that can be traced back to the traditional religion, a cult of spirit possession that the Bakonzo share with other peoples in Eastern Central Africa. The priests are medium therapists called embandwa. The pantheon of spirits is immense. In order to enter into contact with the divinities, the officiants fall into a selfinduced trance by using songs, and above all specific sacred rattles. Drums and the xylophone are essential in some situations such as the purification of crests, the protection of albinos and the celebration of the new moon. ${ }^{31}$

For the Banande on the other hand, in the Eighties (and even today), the relations between the endara and traditional religion were not in any way evident, perhaps because they were inexistent, or perhaps because they were kept secret. The endara was central to their musical culture, but was played on "joyous occasions": festivals, even Christian, the arrival of guests or, quite simply, during the evening's entertainment. ${ }^{32}$ In any case, the Banande had a different relationship with traditional religion from the Bakonzo, due to their earlier and more radical Christianisation. The Missionaries worked in depth, also developing forms of enculturation. For example, the devotion shown towards the Virgin Mary in the area of Beni was implanted onto the cult of a female divinity, Nyabingi. ${ }^{33}$

\footnotetext{
29 "Some Christians, way out in the tropical forest, those who live on the borders of the territory towards Lake Edward, arrive here after several days of walking the day before Christmas Eve. They stay here and there with their friends, and on their arrival, those who are able to receive the sacraments, confess and receive Holy Communion: Not all are able, unfortunately! to receive the Sacraments. Down there, far from the succour of missionaries who can visit them only two or three times a year, mingling with the pagan masses, they return to their sickening polygamy," drawn from (anonymous) Echos de Béni, «L'Afrique Ardente», 4, 1932, p. 7 (my translation from the French). ${ }^{30}$ Sister Relindes interviewed in August 2007.

${ }^{31}$ On the Konzo endara and its symbolic values, see Crupi, The Role and Functions of the Endara Xylophone.

${ }^{32}$ On the value of the endara as an instrument of identity for the Banande, see Facci, I Nande e la loro musica.

${ }^{33}$ Sitone, L'Assomption au Congo (1929-1967.
} 
I have not yet found documents that attest to if or when the endara lost its ancient religious symbology and took on new roles amongst the Banande. Today, however, an endara is played in the Catholic cathedral in Butembo. ${ }^{34}$

As for the dance performed around the endara, there are significant differences in postures and choreography, as though the two peoples started with a common musical repertory and then did their utmost to autonomously invent new forms of dance expression.

The style associated with the Bakonzo endara during ritual occasions is above all the amahande, based on a lateral swaying of the body. If we exclude the Cultural Group shows, based on codified choreographies, the dancers generally move around the xylophone performing free movements. Amongst the Banande people, the endara was danced by alternating two stages: in the first, the dancers moved in a semicircle with small, regular steps; in the second, each dancer performed the shoulder movements, emititiro, at will or else a particular knee-bend with legs wide open. The use of bipartite dances, unknown to the Bakonzo, was instead common among the Banande and, as will be seen in greater depth in the next paragraph, it is really difficult to understand, in the present-day situation, the origins of this difference.

Figure 2 The endara xylophone

\section{Emititiro, ekikuba: inventions, fashions and the search for what is beautiful and new.}

As we have seen in the preceding paragraphs, the comparison of ethnographic data permits the construction of a possible historical process in Banande and Bakonzo dances. The reasons for the processes of change have been sought thus far in the colonial impact on the two cultures. This approach is far from being impartial but it is supported by the availability of more reliable historic documentation, but leaves in the shadow other processes and motivations which have been perpetuated in wholly African places and time periods, for which there is no written evidence. Among the processes that are difficult to reconstruct, there is the entire, extremely important sphere of individual creativity as applied to music and the art of dancing, which most certainly gave rise to the production of new dances, the modification of pre-existing ones, and the absorption of techniques and styles from neighbouring peoples. Some individual innovations would also have been promoted by the communities, eventually becoming representative of the identity of groups or populations. In other words, we are quite simply speaking about the autonomous history of artisticmusical processes.

Ethnomusicologists have only partially tackled this kind of issue, so crucial in the historiography applied to the music of European art: partly because of the objective difficulty in finding reliable documentation in the oral tradition; partly because, in the study of musical cultures, the social function has long been favoured over the aesthetic function.

In this part of my paper I tray to approach this topic with the help of some comments made by Konzo musicians and dancers, during the showing of the film Danze nande (Nande Dances) turned in Bunande in $1988 .^{35}$

\footnotetext{
34 The influence of Christian churches has been deep and far-reaching in Africa, operating by means of prohibitions, the introduction of new repertories and styles (such as certain models of choral singing and instruments like the organ), and enculturation processes which gradually substituted the functions of dances and musical instruments, emptying them of their previous symbolic values. With regard to the dances and percussion instruments which are so widespread in Africa, there have been numerous and varied reactions over time. After the Second Vatican Council, there was a period when they were gradually incorporated into the liturgy itself. See also Agawu, Effetti del colonialismo sulla musica africana.

${ }^{35}$ Danze Nande, by Cecilia Pennacini and Serena Facci, 1989. Interviews with Walina Davis, Gedeon Nzwenge; Savi Balikenga, Matsuza Kabughu, Zebia Masika, Muhasa Andiriya (of the
} 
The research is only in its early stages. Despite this, there were however many interesting observations, all of which concerned the performance techniques, with regard to choreographies, the dancers' movements, and the ways in which the drums were played. The musicians' interest in the contexts or meanings of the dances was limited, even though I struggled to explain them. Below, in summary form, I have listed the various observations:

- Everybody stressed that the drum rhythms, and consequently the dancers' movements, were faster; a younger dancer even observed, correctly in my opinion, that the Bakonzo movements were softer, whereas those of the Banande were more "mechanical".

- The women's movements were often defined as being "like those of the amahande". At present day,, even if I did not notice the existence of that term among the Banande, there is a strong similarity between the basic movement of the amahande and the way in which the Nande women and men let their pelvis turn slightly to the left and right, moving their weight from one foot to the other. Both the Konzo and Nande women tend to emphasise this movement by inserting a piece of hanging material at the back of their skirts, which sways as they move. It should be noted, by the way, that the enhancement of this pelvic movement by means of material, or skirts made of bark or straw, is widespread among other Ugandan peoples, but my impression is that the Nande-Konzo style is particular, and lays less emphasis on the rotating movement of the pelvis than, for example, the Baganda or Basoga people.

- The most characteristic movement in Nande dances is an extremely fast quivering which starts from the shoulders and passes along the arms and hands. This movement is called emititiro. The Bakonzo were very surprised to see it and, even though they knew the meaning of the term (emititiro in Lukonzo means, in fact, "to shake one's shoulders"), they all stated that the Bakonzo do not use this type of movement when dancing. Vice versa, the rapid backwards and forwards undulation of the chest (ekikuba) typical of the ekikebi is totally absent among the Banande, even if the term ekikuba also means "chest" in their language.

- Other symbolic gestures, however, were recognised as being common to both: introflexion of the stomach meaning a state of destitution; opening the palm of the hand forwards to ask for something to eat; bringing a hand to the side of the head to portray a state of pain, a gesture typical of the Bakonzo during their funeral dances, but also used by the Nande men during individual improvisations of the omunde.

- The dance with eluma whistles, seen as comparable to the homonymous Konzo dance, was much criticised by some musicians. In their opinion, the Nande group in the film danced badly, in a sloppy fashion. The complex choreography of the omunde was however completely unknown to them. The omukobo in which two Nande dancers mimed a duel, aroused a knowledgeable and perhaps avid curiosity among the younger Konzo musicians. We should recall that only the memory of this dance remains among the Bakonzo, but its spectacular quality would certainly not disgrace the performance of some Cultural Groups.

Figure 3 Nande omunde dancers

After this experience, my overall impression is that the dances have undergone an entirely African evolutionary process, in total autonomy from colonial influences, primarily due to the need for innovation in the artistic field. It is indisputable, in fact, that the Banande and Bakonzo have the same dance language. On the other hand, other evidence demonstrates how the long period of separation has led them to conjugate differently that need for novelty which is inevitable in the

Maliba Cultural Group); Zedekiya Lhulhanda, Mihandiko John Bosco, Margrate Ithungu Kilhamira, Masika Flora, Kabugho Alice (from Kisamba), recorded in August 2007 
work of musicians and dancers who are more open to invention or metissage, and which is often welcomed favourably by dance communities.

The similarity between the lateral movement of the pelvis, typical of the konzo amahande, and a movement that is very common among the Banande, would seem to confirm that this style belongs to a more ancient level, one in which the connection between this dance and the ritual sphere was more marked.

On the other hand, the two movements involving the upper part of the torso - the quivering of the shoulders, emititiro, and the undulation of the chest, ekikuba - are the clearest indication that, at a certain point, the dance history of these two peoples went its separate ways, elaborating different styles.

When were these movements introduced? The Bakonzo interviewees claim that the ekikebi is a dance which has always existed, as far as they can remember. The emititiro of the Banande is also profoundly rooted in bodily postures, so much so that it is used indistinctly by older people and children. Thus it is not a matter of ephemeral trimmings, or fleeting fashion. If we consider that the division between the two groups occurred in at least the $19^{\text {th }}$ century (or before), it is reasonable to assume that there was plenty of time for these movements to become incorporated in the motorial codes of the two populations, becoming symbols of their identity within living memory.

Perhaps the words expressed by John Blacking in the sentence quoted in the introduction are true: dancing, like song, has its specific and more rapid ways of leading human beings forward in their history of adaptation to environment, towards places of thought that language takes longer to reach and understand.

If this is so, one should also ask oneself why these two communities wished to perceive and portray themselves precisely through these movements involving the upper part of the torso, differently from the people of central Uganda, for example, (in primis the Baganda) who use the pelvis much more; and what lies behind the variation in these two movements.

From the observer's point of view, the ekikebi, particularly amongst the women, could lay an emphasis on the erotic nature of the breasts' movement. However, the person dancing perceives above all the pleasure of flexing the rib cage, the most rigid part of the body.

In the emititiro, on the other hand, there is a great show of strength in the back, the quivering that starts from the shoulders, passes right down to the tips of the fingers. I am not able to imitate the movement, but I think it must be very pleasurable to vibrate an entire area that is so intensely involved in breathing and also so close to the head. The latter remains unbelievably still, and impassive in its expression, but even as it resists the movement, it cannot possibly ignore the strength of the "earthquake" which runs through the shoulder muscles.

\section{Media and Cultural Groups: an outline of how modernity functions}

For many decades now, the Banande-Bakonzo have been completely immersed in the spread of new African musics and dances that are influenced by Anglo-Afro-American models.

The Bakonzo, like other Ugandans, generically define the sum total of these musics and dances with the terms muziki and disco. These repertories exist and circulate thanks primarily to the media (a lot of radio, many cassettes, a little TV, the occasional CD and, today, many MP3s), or thanks to performances.

Traditional dances also, partially, use these circuits.

I would like to report two cases in which the media and the modern organisation of performances have played a role in the cultural exchange between Banande e Bakonzo.

The first concerns the omunde. This dance was extremely popular amongst the Banande in the Eighties, not least because a group of dancers had had the opportunity of participating in an international folklore festival in Belgium and subsequently in Canada. In the profoundly difficult political-economic situation in Zaire at that time, the possibilities of leaving the country were very limited indeed. As with many other African areas in the post-independence period, for the 
Banande, too, the new age of the dance-show was inaugurated, an opportunity that offered work and emancipation to young musicians and dancers.

In 2007, the organiser of a Bakonzo Cultural Group in Bwera, a small town on the border between Uganda and Congo, told me that his group had recently learnt to perform the omunde, a dance which, as we have said, was unknown to the Bakonzo. Some dancers had seen a Nande group dancing it during a performance, and he himself knew it, since he travels a great deal on business. Similarly, in 1986 I had also seen a dance, called akasayi, that some Banande said they had learnt from the Bakonzo in villages close to the border.

The second case concerns the amatakio performed by young Nande women. This wedding dance, which probably emerged under the influence of the missionaries, was also influenced by the Catholic school education of the girls. The wedding songs were sometimes interspersed with short theatre plays of an instructive content, or songs in French that the young women had learnt at school.

In a previous paragraph, I said that it is unknown to the Bakonzo, but this is not entirely true. It would appear that a kind of "amatakio" spread through the Ugandan area in the Sixties and Seventies, but it was a very different dance: "It was danced in a circle, each person alone, like disco dancing. It was a new dance." ${ }^{36}$ It seems that the Bakonzo closest to the border had heard the amatakio when listening to some Congolese programmes on the radio. They thus learnt only the sound elements and used it as a fun dance, improvising the way of dancing it.

With regard to the Bakonzo, we should take a last look at the educational institution and that of the Cultural Groups which emerged after independence. The Ugandan school system, which was derived from the British one, encourages the teaching of various performance arts in primary and secondary schools: choral singing (in English with a European style), poetry, instrumental ensembles, theatre, artistic dance and traditional dance.

The traditional dances require the training of instrumentalists, singers and dancers, as well as the creation of a choreography, which is presented in the form of a performance during the many school competitions promoted at local and national level. The ekikebi, like the amahande, is thus a subject studied by the Konzo youth: and since the didactics need clear rules and equally clear verbalisations, these two dances are now learnt by most of the young people in a form that is more conscious, but at the same time more stereotyped, than that practised by the older people. We could set this process in the context of those forms of "folklorising" tradition, whose outcome is well-known in Europe. Whether one works towards superseding the "ancient" culture in the name of modernisation processes, or if one wishes to exalt such art forms by involving them in a revival process, one can operate only by implanting new processes of change. The case of Uganda, in this regard, is particularly interesting, since some interventions aimed at preserving tradition acted through the school and cultural associations, directly recalling the English folk revival with its tradition that goes back more than a hundred years. ${ }^{37}$

\section{Conclusions}

The aim of this article was to compare the dances of the Banande and Bakonzo and show how a practice regarding the artistic-expressive sphere, deeply rooted in the life of these two peoples, is steeped in a complex flow of events. I hope that it has proved clear how the intricate interweaving of dance, music, expressive and aesthetic needs, community customs, religious practices (and anything else that contributes to creating the existence of a group), has accompanied these two populations over the past century.

\footnotetext{
${ }^{36}$ Gedeon Nzwenge, interviewed in August 2007.

${ }^{37}$ See also Nannyonga-Tamusuza, Competitions in school Festivals.
} 
The separation that occurred between the Banande and Bakonzo, never experienced as definitive, is manifested through their dances in terms of different colonial experiences and also different aesthetic choices. Conversely, the original kinship emerges in the common memory of ritual dances and in some motorial behaviours that distinguish the Banande-Bakonzo from other peoples in the area. Unfortunately, the scarcity of documentary sources causes the conclusions to be hypothetical, and those selfsame oral sources, available through field research, deserve to be enlarged and extended also to areas with which I, like other researchers, have not had the opportunity to come into contact.

If it has been possible to carry out this research, merit is however due in the final analysis to the richness of these two peoples' dance repertories, and the enormous generosity with which the Banande and Bakonzo (totally similar in this respect) perform their dances and speak about them. I noticed that this helpfulness, even towards a foreign researcher like myself, was often marked by considerable enthusiasm due to the fact that my request to watch and analyse the performances simply offered yet another opportunity, sometimes unexpected, to dance. The pleasure of dancing is universally recognised. The strength of dancing as a means of feeling part of a group and communicating with the otherworld, is also a sensitive element in the culture of numerous peoples, including many in Africa.

The Banande and Bakonzo, despite the numerous vicissitudes they have undergone in the various phases of their history, and despite the attacks directed particularly at their ways of dancing, have managed to safeguard those dances. Although subjecting them to changes and sometimes compromises, they have tried nonetheless to maintain intact their aesthetic, communicative and cohesive force.

As assumed by Michel Foucault, the body is the only affordable wealth for poor and subjected people. The care and exaltation of the body in dance must have been a great resource in the numerous dark periods experienced by these and other peoples in Africa and throughout the world and the ability to keep dances alive is essentially a sign of resistance against the harshness of history. ${ }^{38}$ In particular, the capacity to create new dances and new styles, witnessed by the differences between Banande and Bakonzo, is a sign of good health of these two cultures.

\section{References}

Agawu, Kofi. "Effetti del colonialismo sulla musica africana”, in Enciclopedia della Musica. Vol V L'unità della musica, edited by Jean Jacques Nattiez, Torino: Einaudi, 2005: 5-31.

Amselle, Jean-Loup. Logiques Métisses . Anthropologie de l'identité en Afrique et ailleurs, Paris, Éditions Payot \& Rivages, 1990 (English Edition : Mestizo Logics. Anthropology of Identity in Africa and Elsewhere, Stanford : Stanford University Press, 1998 (translated by Claudia Royal).

Arom, Simha. Polyphonies et polyrythmies instrumentales d'Afrique Centrale, Paris : Selaf, 1985.

Bergmans, Lieven. Nova et vetera. À propos dela vie, la mort et surtout de l'enterrement de Joseph Biundi Inoghoreria grand chef des Baswaga, Butembo (Zaire), 1975.

Blacking, John. 'A Commonsense view of all Music', Cambridge-New York: Cambridge University Press, 1987.

Cooke, Peter, Doornbos, Martin. "Rwenzururu Protest Songs", Africa, 32, no.1 (1982): 37-53.

\footnotetext{
${ }^{38}$ See, about African-American slavery, Malone, Steppin' on the Blues.
} 
Crupi, Vanna. "The Role and Functions of the Endara Xylophone among the Bakonzo People", in, Rwenzori. History and Cultures of an African Mountain, edited by C. Pennacini, H. Wittenberg. Kampala: Fountain Publishers, 2007: 253-284.

Czekanowski, Jan. Carnet de route au coeur de l'Afrique. Des source du Nil au Congo, Montricher (CH) : Editions Noir sur blanc, 2001.

Facci, Serena, Nanyonga-Tamusuza Sylvia., "Continuity and Change in Bakonzo Music: From 1906, to 2006", in Rwenzori. History and Cultures of an African Mountain, edited by C. Pennacini, H. Wittenberg, Kampala: Fountain Publisher: 223-252.

Facci, Serena. "I Nande e la loro musica", in Etnografia Nande III, Torino: Il Segnalibro, 1997: 11-57.

Green, Doris. "Traditional dance" in African Dance. An Artistic Historycal **Historical** and Philosophical Inquiry, edited by K. Welsh-Asante, Asmara (Eritrea): African World press, 1998: 13-28.

Hanna, Judith Lynne. To Dance is Human: A Theory of Nonverbal Communication, Chicago: University Of Chicago Press, 1987.

Kubik, Gerhard. "Nuove ricerche sul campo nel regno del Buganda, 2000 e 2002. Una retrospettiva storica, antropologico-culturale ed etnomusicologica", in Incontri di etnomusicologia. Seminari e conferenze in onore di Diego Carpitella, edited by G. Giuriati, EM Quaderni, Roma: Archivi di Etnomusicologia dell'Accademia di S. Cecilia, 2007.

Lowen, Alexander. The Language of the Body. Physical Dynamic and Character, New York: Macmillan, 1958.

Malone, Jacqui. Steppin' on the Blues: The Visible Rhythms of African American Dance Champaing (IL): University of Illinois Press, 1996.

Mbabazi, Pamela, Kikibi dance of the Bakonzo, Master diss., Makerere University, Kampala 2003.

Mashauri, K. T. Organisation étatique des Yira, et son origine, in La civilization ancienne des peoples des Grands Lacs, Paris : Karthala,1981 : 160-169.

Nannyonga-Tamusuza, Sylvia, "Competitions in school Festivals: A Process of Re-inventing Baakisimba Music and Dance of the Baganda (Uganda)", World of Music, 45, no.1 (2003): 97-118.

Pennacini, Cecilia. Alle falde del Ruwenzori. Etnologia di una frontiera africana-On the slopes of the Ruwenzori. Ethnology of an African frontier in I popoli della luna. Ruwenzori 1906-2006-The peoples of the moon. Ruwenzori 1906-2006, edited by Id., Torino: Cahiers Museo della Montagna, 2006: 79-96.

Pennacini, Cecilia. "Danze nande”, in Etnografia Nande III, Torino: Il Segnalibro, 1996: 59-90.

Peterson Royce, Anya. Anthropology of dance, Bloomington (IN): Indiana University Press, 1980.

Remotti, Francesco. Etnografia nande I, Torino: Il Segnalibro, 1993. 
Sachs, Curt. Eine Weltgeschichte des Tanzes, Berlin: Dietrich Reimer, 1933 (Italian Edition: Storia della danza, Milano: Il Saggiatore 1966).

Sitone, Matthieu. " L'Assomption au Congo (1929-1967)", in L'aventure missionaire Assomptionniste, Actes du Colloque d'Histoire du $150^{\mathrm{e} m e}$ anniversaire de la Congregation des Augustins de l'Assomption, Lyon Valpré, 22-26 novembre 2000, edited by Bernard Holzer, Collecxtion Recherches Assumption, n.1, 2000: 519-542.

Stacey, Tom. Tribe. The Hidden History of the Mountain of the Moon, London: Stacey International, 2003.

Thomas, Helen. Dance, Modernity and Culture: Explorations in the Sociology of Dance, London: Routledge, 1995.

Waswandi, Kalule Ngoliko. Le Munde. La danse de l'épervier, Butembo (Zaire), 1984.

Welsh Asante, K. ed. African Dance. An Artistic Historycal and Philosophical Inquiry, Asmara: African World press, 1998. 